\title{
Article \\ Field campaign evaluation of sensors GMX500 and WS100 in Peruvian central Andes
}

\author{
Jairo M. Valdivia ${ }^{1, \ddagger(\mathbb{D}}$, David A. Guizado ${ }^{1, \ddagger(\mathbb{D}}$, José L. Flores-Rojas ${ }^{1, \ddagger * \mathbb{D}}$, Delia P. Gamarra ${ }^{2} \mathbb{D}$, Yamina F. Silva $^{3} \mathbb{D}$, \\ Rosana E. Huamán ${ }^{2}$ and Luis F. Suarez ${ }^{1}$ (iD) \\ 1 Instituto Geofísico del Perú, Lima 1502, Peru; jvaldivia@igp.gob.pe (J.M.V.); alejandroguivi@e-mail.com \\ (D.A.G); \\ 2 Universidad Nacional del Centro del Perú 3909, Perú; d.gamarra@uncp.edu.pe (D.P.G.); e-mail@e-mail.com; \\ ehuaman@uncp.edu.pe (R.E.H.) \\ 3 Instituto Nacional de Investigación en Glaciares y Ecosistemas de Montaña, Perú; fsilva@inaigem.gob.pe \\ (Y.F.S); \\ * Correspondence: jflores@igp.gob.pe; Tel.: +51-924-133-957 \\ $\ddagger \quad$ These authors contributed equally to this work.
}

\begin{abstract}
The research presents the inter-comparison of atmospheric variables measured by 9 automatic meteorological stations. This set of data was compared with the measurements of other meteorological stations in order to standardize the values that must be adjusted when taken to different areas. The data of a set of a total of 9 GMX500, which measures conventional meteorological variables, and 10 WS100 sensors, which measures precipitation parameters. The automatic stations were set up at the Huancayo Observatory (Geophysical Institute of Peru) for a period of 5 months. The data set of GMX500 were evaluated comparing with the average of the 9 sensors and the WS100 was compared with a optical disdrometer Parsivel ${ }^{2}$. The temperature, pressure, relative humidity, wind speed, rainfall rate, and drop size distribution was evaluated. A pair of GMX500 sensors presented high data dispersion, it was found found that the errors came from a bad configuration; once this problem was solved, good agreement was archived, with low RMSE and high correlation. I was found that the WS100 sensors overestimate the precipitation with a percent bias close to $100 \%$ and the differences increase with the greater intensity of rain. The DSD retrieved by WS100 have unrealistic behavior with higher concentrations in diameters of $1 \mathrm{~mm}$ and $5 \mathrm{~mm}$, in addition to a flattened curve.
\end{abstract}

Keywords: Meteorological instruments; Drop size distribution; DSD; Huancayo Observatory; Peruvian Central Andes

\section{Introduction}

In this work, the Lufft WS100 and MaxiMet GMX500 are used as part of a weather station, which would have the objective of covering most of the measurements necessary in research related to meteorology. Through a compact, automated and energy-efficient design, the Lufft WS100 and MaxiMet GMX500 are presented as one of the best options to carry out studies in areas of complex topography where data are scarce, such as the Andes. Lufft WS100 is a rain sensor, which uses a $24 \mathrm{GHz}$ Doppler radar to measures all kind of precipitation with the possibility of retrieve the drop size distribution (DSD). MaxiMet GMX500 is an advanced compact weather station which uses proved technology to measure wind speed and direction, humidity and pressure, with no moving parts. The MaxiMet has a broad range of compact weather stations designed and manufactured by Gill Instruments, several of these instruments has been used previous research (e.g., Matthews et al. 1, Cheng et al. 2, Danezis et al. 3, Wright et al. 4) showing that they are reliable instruments. In the other hand, the Lufft is a brand of OTT Hydromet and has been developing and producing professional components for climate and environment 
for more than 135 years. Some OTT instruments such as the optical disdrometer Parsivel ${ }^{2}$ have been extensively used and evaluated (e.g., Tokay et al. 5, Park et al. 6, Raupach and Berne 7, Valdivia et al. 8,9, Del Castillo-Velarde et al. 10). However, the Lufft WS100 rain sensor practically unknown in the scientific world and there are no studies evaluating how reliable its DSD retrievals are, as the Parsivel $^{2}$ does.

There is interest in being able to use the WS100 instead of the Parsivel2 since the WS100 sensor is much cheaper than the Parsivel ${ }^{2}$ and, based on information provided by the manufacturers, is capable of providing similar information. The Particle Size Velocity (Parsivel) is an optical disdrometer that measures both, size and velocity of the hidrometeors [11]. OTT then presented a second version of the Parsivel called Parsivel ${ }^{2}$, providing some improvements over its predecessor. Tokay et al. [5] evaluated the Parsivel ${ }^{2}$ with other types of disdrometers finding good agreement especially in middle drop diameters ( 0.5 to $4 \mathrm{~mm}$ ), and compared to rain gauge the Parsivel $^{2}$ had a $6 \%$ absolute bias in the event rain totals. Further comparisons of the Parsivel $^{2}$ with $2 \mathrm{D}$-video disdrometers have shown that the Pasivel ${ }^{2}$ underestimates drops smaller than $0.76 \mathrm{~mm}$ and overestimates drops greater than $4 \mathrm{~mm}$ [12], and corrections have been proposed to improve data quality [6,7]. Valdivia et al. [9] compared the Parsivel ${ }^{2}$ with tipping bucket rain gauges and a couple of radar profilers in the central Andes (3315 m MSL), founding a systematic underestimation in the event rain totals (18\% bias and 19\% absolute bias). However the Parsivel ${ }^{2}$ measurements are even more reliable than those provided by radar, and DSD retrievals are necessary for the radar algorithms optimization [13].

In order for the Lufft WS100 and MaxiMet GMX500 to be used with complete confidence in the future research studies, an analysis of the quality of his data is necessary. In the present study, an inter-comparison is made between 10 compact stations, which are assembled with the WS100 rain sensor and GMX500 weather station. The experimental study also includes a Parsivel ${ }^{2}$ which is used as reference for rain measurements and DSD evaluation. The technical details of the instruments are provided in section 2 . The results of the inter-comparison between instruments are shown in section 3. The discussions is presented in section 4 , followed by the conclusions in section 5 . This work aims to show what is the real performance of these instruments as well as highlight their strengths and weaknesses.

\section{Materials and Methods}

\subsection{Site of measurements}

The measurements of the meteorological variables in this study were carried out at the Huancayo Observatory (12.03 S, 75.32 W, 3315 m MSL), which is located in the Andes between Cordillera Occidental and Huaytapallana Cordillera, Peru. The data was collected from October 18, 2020 to January 31, 2021. 10 automatic stations were installed at a horizontal distance of $3.5 \mathrm{~m}$ and the instruments at $2 \mathrm{~m}$ from the ground surface in a north-south direction on tripods placed in the study area (see Figure 1). Of all the stations, 9 were acquired by the "CEPREANDES" project (sensor 1-9) and 1 station (sensor 10) was included in October 2020 as part of a collaboration of the "CEPREANDES" project. The study was carried out in a total area of. The precipitation measurements come from a rain sensor WS100 and Pasivel$^{2}$, the temperature, pressure, relative humidity and wind velocity from the Maximet GMX500. The assembly of each station was meticulously carried out taking care of the norms for the installations of automatic meteorological stations. 


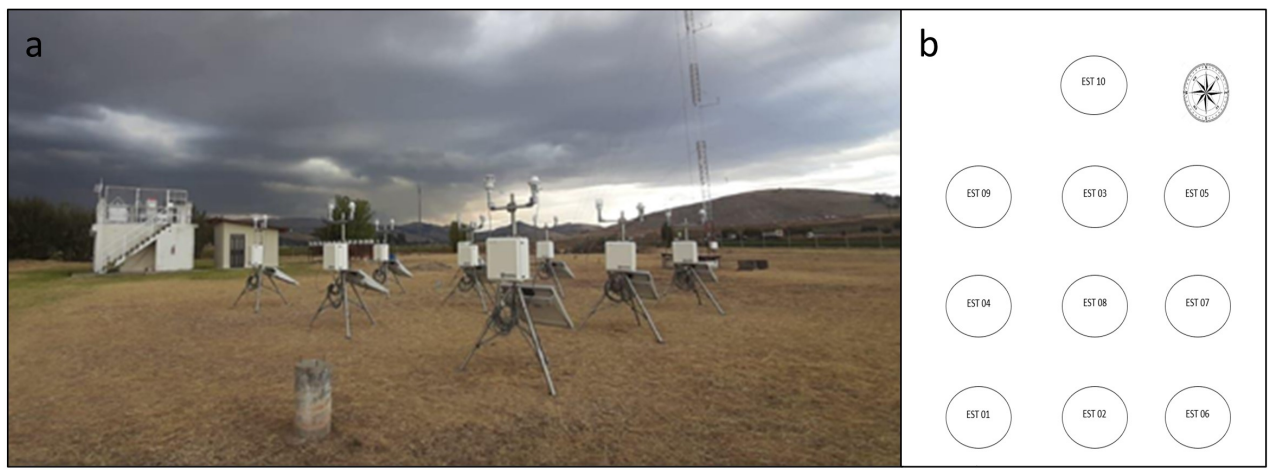

Figure 1. Distribution of the compact automatic stations in the site of study. (a) Picture of the installed compact automatic station in the Huancayo Observatory. (b) Distribution of the 10 stations, which have $3.5 \mathrm{~m}$ of the horizontal and vertical separation.

\subsection{Instrumentation}

\subsubsection{Compact automatic stations}

The 10 compact automatic stations are assembled in the same way. Cables for the installation of sensors, battery, solar panel and datalogger. The cables connect the rain sensor to the datalogger, like the meteorological sensor, a cable from the solar panel goes directly to the datalogger and another to the battery. Figure 2 shows the components of the stations. The detailed description of each component in the automatic station is presented as follow:

- Weather Sensor GMX500 MAXIMET GILL series (Figure 2a): MaxiMet is an advanced compact weather station, designed and manufactured by Sensovant Instruments using proven technology to measure meteorological and environmental parameters to international standards. Measurement parameters: wind, temperature, humidity, pressure, compass, GPS (optional).

- WS100 Lufft Precipitation Sensor (Figure 2b): A Smart Disdrometer, using a $24 \mathrm{GHz}$ Doppler radar, it measures the speed of all forms of condensed water. These include rain, freezing rain, hail, snow, and sleet. The low energy sensor detects precipitation from the first drop.

- Campbell Scientific Box (Figure 2c): The ENC16/18 cabinet, the back plate of the ENC16/18 is pre-drilled with half-inch holes in the center suitable for connecting a data logger, a power supply, and a communications or measurement and control peripheral.

- $\quad$ Stainless steel tripod (Figure 2d): The CM110 is a 10-foot instrumentation tripod that supports mounting of sensors, mounts, solar panels, and environmental enclosures. Constructed of stainless steel, the CM110 is easier to transport to remote locations. The tripod can be deployed on uneven terrain and at varying heights

- Datalogger CR310 - CAMPBELL SCIENTIFIC (Figure 2e): The CR310 is a low-cost, compact, multipurpose measurement and control datalogger that has an integrated 10/100 Ethernet port and removable terminal blocks. This entry-level datalogger, with its powerful set of programmable instructions, can measure most sensors for hydrology, meteorology, environment and industry. As a data concentrator, it makes data available through a variety of telecommunications networks and protocols. The CR310 has decision-making capabilities, perfect for M2M communications and control applications. The CR310 is ideal for basic remote long-term monitoring and control applications.

- $\quad$ Automatic station battery Ritar 12v 65Ah AGM (Figure 2f): The Ritar brand solar gel battery has a capacity of 65Ah and has been designed for use in small and mediumpower solar installations. Thanks to its component in the form of a gel, it offers a much higher performance. It has an approximate useful life of 10 years and does not require maintenance. 
- $\quad$ SP30 solar panel (Figure 2g): The SP30 is a 30W solar panel. It is commonly used in systems that have higher than average power requirements, or in high mountain stations. It connects to our power supplies or regulators to charge the battery, and thus allows unattended operation of our systems in remote locations without the need for $220 \mathrm{Vac}$

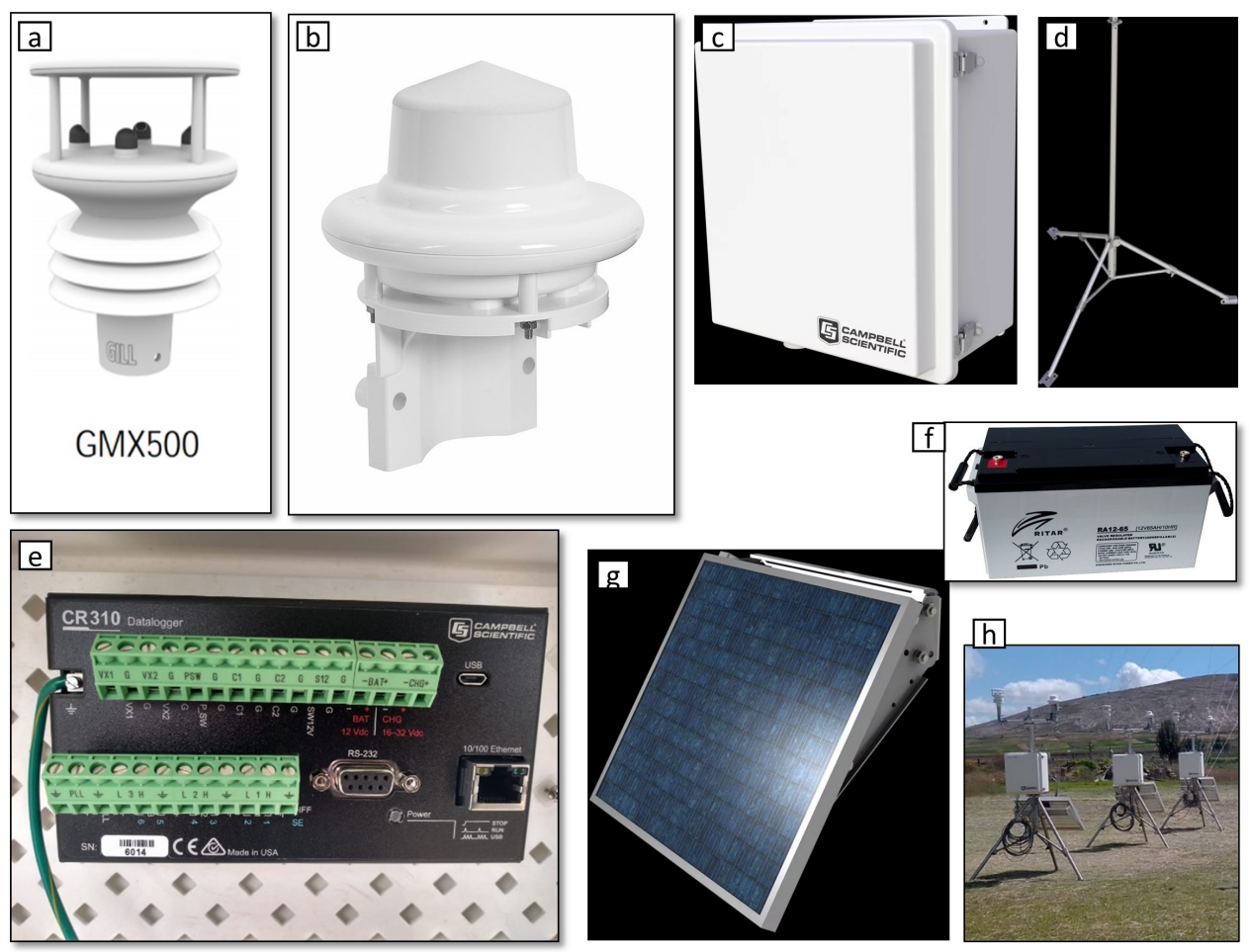

Figure 2. Components of the automatic compact stations. (a) Weather Sensor GMX500 MAXIMET GILL series. (b) WS100 Lufft Precipitation Sensor. (c) Campbell Scientific Box. (d) Stainless steel tripod. (e) Datalogger CR310 - CAMPBELL SCIENTIFIC. (f) Battery Ritar 12v 65Ah AGM. (g) SP30 solar panel. (h) Final assembled stations.

\subsubsection{The OTT Parsivel ${ }^{2}$}

The OTT Parsivel ${ }^{2}$ is alaser optical disdrometer. The unit works on the principle of extinction and measures the particles precipitated from the shadow they generate when they pass through a laser band [11]. From the raw data obtained, the amount and intensity of rainfall, visibility conditions, kinetic energy and radar reflectivity of rainfall are calculated. The raw output provides the drops numbers in a $32 \times 32$ size versus velocity array. The size range is 0 to $25 \mathrm{~mm}$, and the class width increase from 0.125 to $3 \mathrm{~mm}$. Due to the low signal to noise ratio the first two size classes are left empty. The minimum detectable size is $0.25 \mathrm{~mm}$. The fall velocity range is from 0 to $20 \mathrm{~m} \mathrm{~s}^{-1}$, and the class width increase with the velocity.

\subsection{Data analysis}

The data from the GMX500 and WS100 of the compact automatic station are analyzed separately. The GMX500 data are inter-compared using the average of all stations as a reference. The GMX500's variables to be evaluated are: temperature, pressure, relative humidity, and wind intensity. The coefficient of determination $\left(R^{2}\right)$, the root mean square error (RMSE) and a linear regression are calculated for each station. WS100 data is evaluated using Parsivel $^{2}$ as a reference. The total accumulated rainfall per event, the rainy minutes, the rain intensity, and the drop size distribution (DSD) measured for each event are evaluated separately. To be consistent with the metric from previous studies (i.e. Tokay 
et al. 5, Valdivia et al. 9), the statistics used in the rainfall evaluation are: the bias, relative bias, absolute relative bias and Pearson correlation.

\section{Results}

3.1. Inter-comparison of GMX500

\subsubsection{Temperature}

The first inter-comparison made between GMX500 sensors is temperature. The average of the 9 sensors was used as a reference to evaluate each sensor. Figure 3 shows the inter-comparisons of each sensor, which are enumerated in each panel. It can be seen that sensors 1 and 2 differ considerably from the other sensors (Figure 3a, b). While almost all sensors have an $\mathrm{R}^{2}$ greater than 0.99 , Sensors 1 and 2 have an $\mathrm{R}^{2}$ of 0.62 and 0.96 , respectively. Sensor 1 has a higher dispersion of its data, its RMSE is 2.65 C (Figure 3a), followed by Sensor 2 with 0.85 C (Figure 3b), then Sensor 9 with an RMSE of 0.44 C (Figure 3i). The rest of the sensors (i.e. 3-8) have an RMSE between 0.2 and $0.3 \mathrm{C}$ (Figure $3 \mathrm{c}-\mathrm{h}$ ). The evaluation of the linear regression indicates that all the sensors have a tendency close to the ideal (i.e. intercept equal to 0 and slope equal to 1 ), except, sensor 1 whose intercept is 2.74 and the slope is 0.787 (Figure 3a). The other sensors had an intercept less than 0.153 and the slope greater than 0.99 (Figure $3 b-i)$. The statistical results of all the sensors are shown in Table 1.
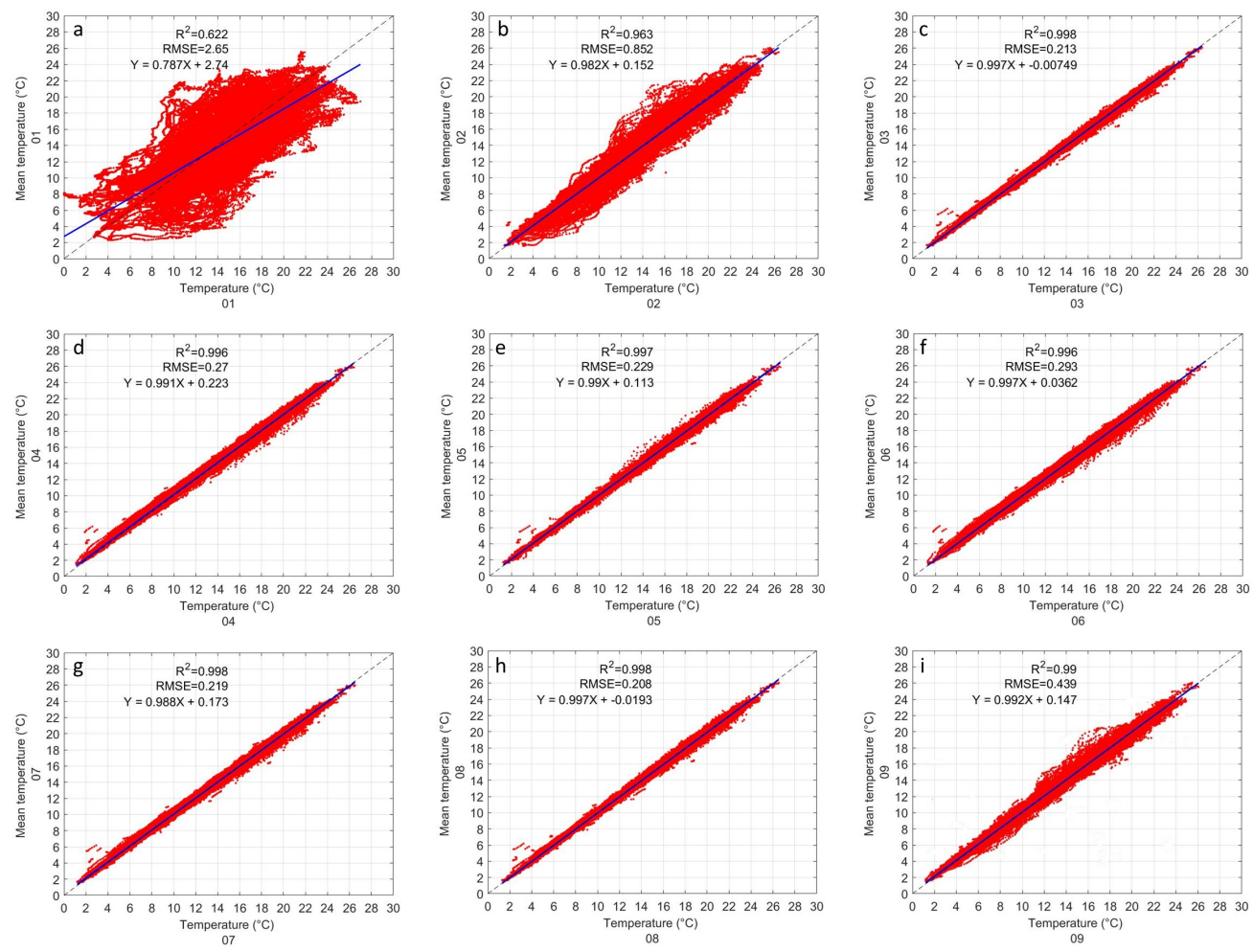

Figure 3. Inter-comparison of temperature between GMX500 sensors. The coefficient of determination $\left(R^{2}\right)$, the root mean square error (RMSE) and the lineal regression are shown in each panel. 
Table 1. statistical results of the inter-comparison of the temperature of the GMX500 sensors.

\begin{tabular}{ccccc}
\hline \multirow{5}{*}{ Sensor } & $\mathrm{R}^{2}$ & RMSE & Slope (a) & Intercept (b) \\
\hline 1 & 0.622 & 2.650 & 0.787 & 2.740 \\
2 & 0.963 & 0.852 & 0.982 & 0.152 \\
3 & 0.998 & 0.213 & 0.997 & -0.007 \\
4 & 0.996 & 0.270 & 0.991 & 0.223 \\
5 & 0.997 & 0.229 & 0.990 & 0.113 \\
6 & 0.996 & 0.293 & 0.997 & 0.036 \\
7 & 0.998 & 0.219 & 0.988 & 0.173 \\
8 & 0.998 & 0.208 & 0.997 & -0.019 \\
9 & 0.990 & 0.439 & 0.992 & 0.147 \\
\hline
\end{tabular}

\subsubsection{Pressure}

Pressure inter-comparison shows great similarity between all instruments to the naked eye. The inter-comparison of all instruments is shown in Figure 4 . The $\mathrm{R}^{2}$ are very close to 1 in all cases. Sensors 1 and 2 have a slightly lower R2 than the rest (0.94 and 0.98, respectively), while all other sensors exceed 0.99 . It can be seen, in sensor 1 (Figure $4 \mathrm{a}$ ) that there are some outliers that form a straight line at $687 \mathrm{hPa}$, and in sensor 2 (Figure $4 \mathrm{~b})$ that there is greater dispersion of the data. In all sensors the RMSE is less than $0.1 \mathrm{hPa}$, except for sensors 1 and 2 which have 0.453 and $0.266 \mathrm{hPa}$, specifically. In the evaluation of the linear regression, it can be seen that the slope is almost perfect in all cases without exception $(\mathrm{a}>0.98)$. On the other hand, the intercept varies from -4.65 in sensor 5 (Figure $4 \mathrm{e})$ to 12.2 in sensor 7 (Figure $4 \mathrm{~g}$ ). The statistical results of all the sensors are shown in Table 2.
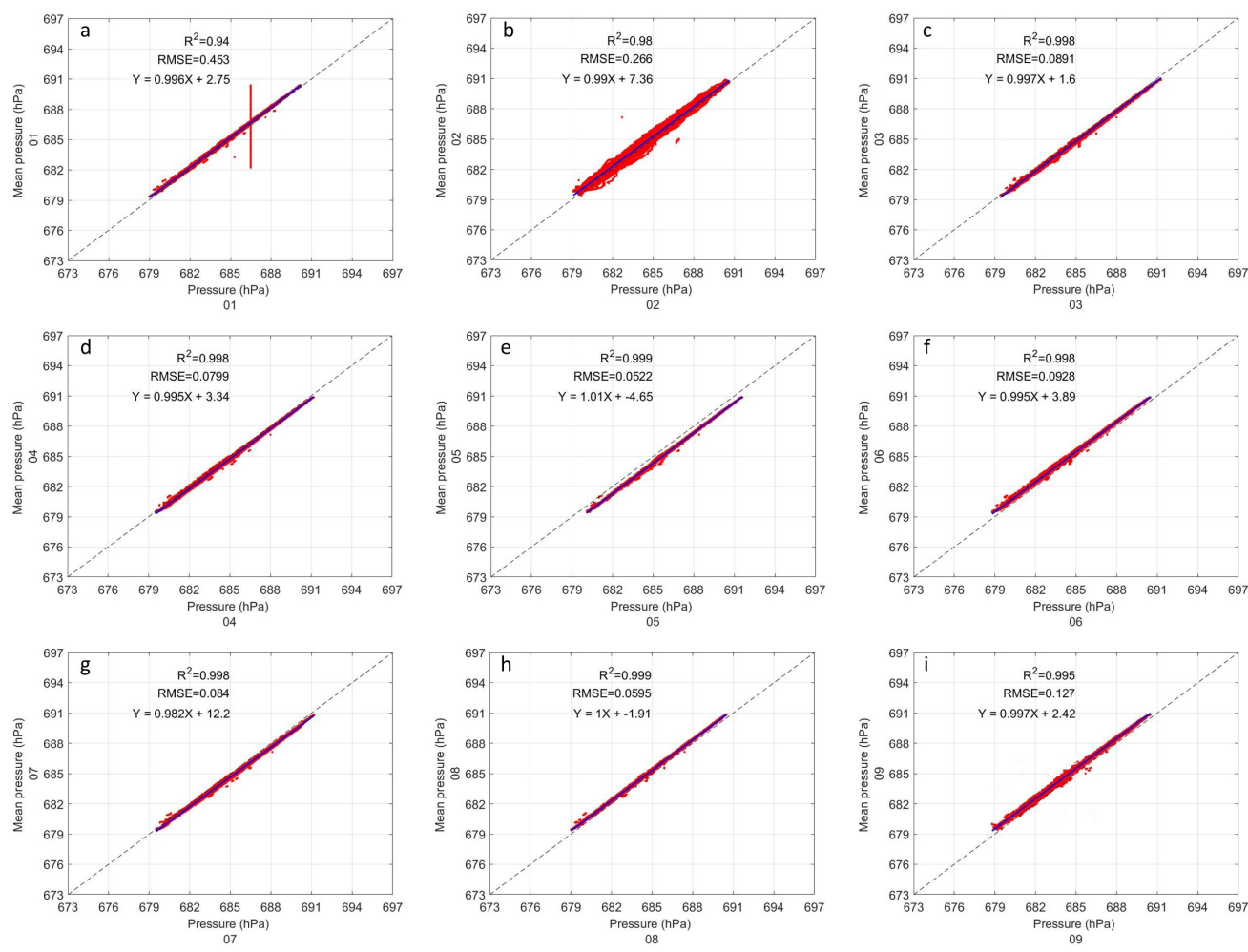

Figure 4. Same as Figure 3 but for pressure. 
Table 2. statistical results of the inter-comparison of the Pressure of the GMX500 sensors.

\begin{tabular}{ccccc}
\hline \multicolumn{5}{c}{ Pressure } \\
\hline Sensor & R2 & RMSE & Slope (a) & Intercept (b) \\
1 & 0.940 & 0.453 & 0.990 & 2.75 \\
2 & 0.980 & 0.266 & 0.990 & 7.36 \\
3 & 0.998 & 0.0891 & 0.997 & 1.60 \\
4 & 0.998 & 0.0799 & 0.995 & 3.34 \\
5 & 0.999 & 0.0522 & 1.010 & -4.65 \\
6 & 0.998 & 0.0928 & 0.995 & 3.89 \\
7 & 0.998 & 0.084 & 0.982 & 12.20 \\
8 & 0.999 & 0.0595 & 1.000 & -1.91 \\
9 & 0.995 & 0.127 & 0.997 & 2.42 \\
\hline
\end{tabular}

\subsubsection{Relative Humidity}

All GMX500 sensors appear to be fairly close in relative humidity inter-comparison (Figure 5). Sensor 1 (Figure 5a) presents outliers in the same way as in pressure (Figure 4a), which apparently decreases its R2 to 0.957. All other sensors (Figure 5b-i) have an R2 greater than 0.99. In Figure 5 it can be observed that all the sensors have a similar data dispersion, with the exception of sensor 5 . Sensor 5 has greater dispersion in our data with an RMSE equal to 1.33, only surpassed by sensor 1 due to its outliers. The RMSE of the other sensors (i.e. Figure $5 \mathrm{~b}-\mathrm{d}, \mathrm{f}-\mathrm{i}$ ) are less than 0.1 . The linear regression of all sensors appears to be perfect to the naked eye, the slope values range from 0.99 to 1.02 and the intercept values range from 1.12 to -0.86 . The statistical results of all the sensors are shown in Table 3.
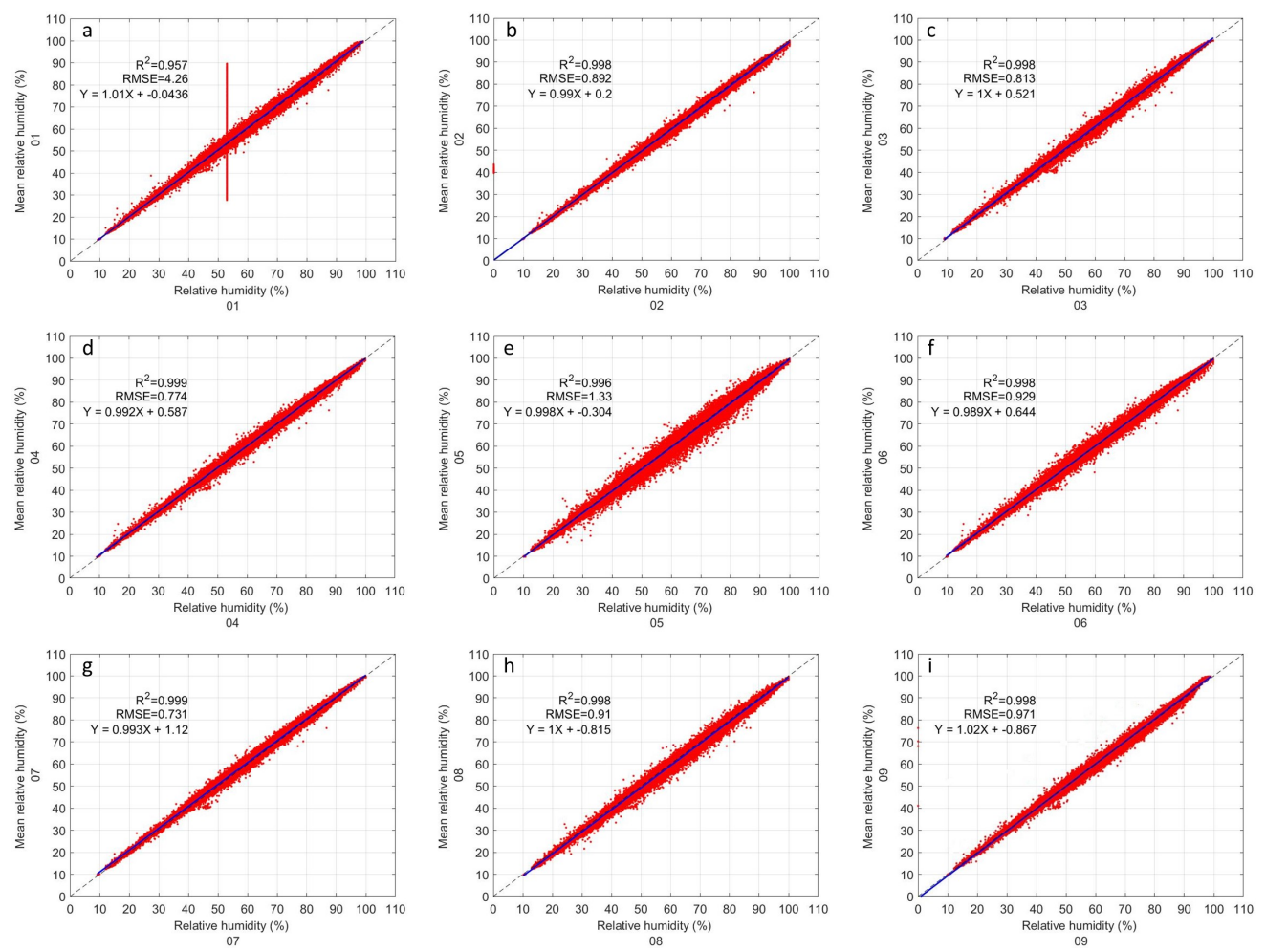

Figure 5. Same as Figure 3 but for relative humidity. 
Table 3. statistical results of the inter-comparison of the Relative Humidity of the GMX500 sensors.

\begin{tabular}{ccccc}
\hline \multirow{2}{*}{ Sensor } & R2 & Relative Humidity & \\
& RMS & Slope (a) & Intercept (b) \\
\hline 1 & 0.957 & 4.260 & 1.010 & -0.044 \\
2 & 0.998 & 0.892 & 0.99 & 0.200 \\
3 & 0.998 & 0.813 & 1.000 & 0.521 \\
4 & 0.999 & 0.774 & 0.992 & 0.587 \\
5 & 0.996 & 1.330 & 0.998 & -0.304 \\
6 & 0.998 & 0.929 & 0.989 & 0.644 \\
7 & 0.999 & 0.731 & 0.993 & 1.120 \\
8 & 0.998 & 0.91 & 1.000 & -0.815 \\
9 & 0.998 & 0.971 & 1.02 & -0.867 \\
\hline
\end{tabular}

\subsubsection{Wind Velocity}

The inter-comparison of the wind speed shows much more dispersed data than in the previous variables (Figure 6). Despite the dispersion in the data, all the sensors seem to behave the same way. Sensor 1 returns to showing straight line outliers near $3 \mathrm{~m} \mathrm{~s}^{-1}$ (Figure 6a). For this variable, the R2 in all sensors quite low compared to the other variables. Sensor 1 has the lowest R2 (0.724), but just lower than sensor 5 (0.728). Sensor 9 has the highest R2 with 0.83 . The RMSE of all instruments is similar. Sensor 1 and 5 have the highest RMSE with $0.567 \mathrm{~m} \mathrm{~s}^{-1}$ (Figure 6a, e). While the lowest RMSE is from sensor 9 with $0.446 \mathrm{~m} \mathrm{~s}^{-1}$ (Figure 6i). Linear correlation analysis shows a low slope in all cases. Sensor 1 has the lowest slope at 0.745 , while Sensor 7 has the highest slope at 0.814 . The intercept in all cases is similar, sensor 9 has the lowest intercept $(0.278)$ and the highest is that of sensor 5 (0.341). The statistical results of all the sensors are shown in Table 4 .
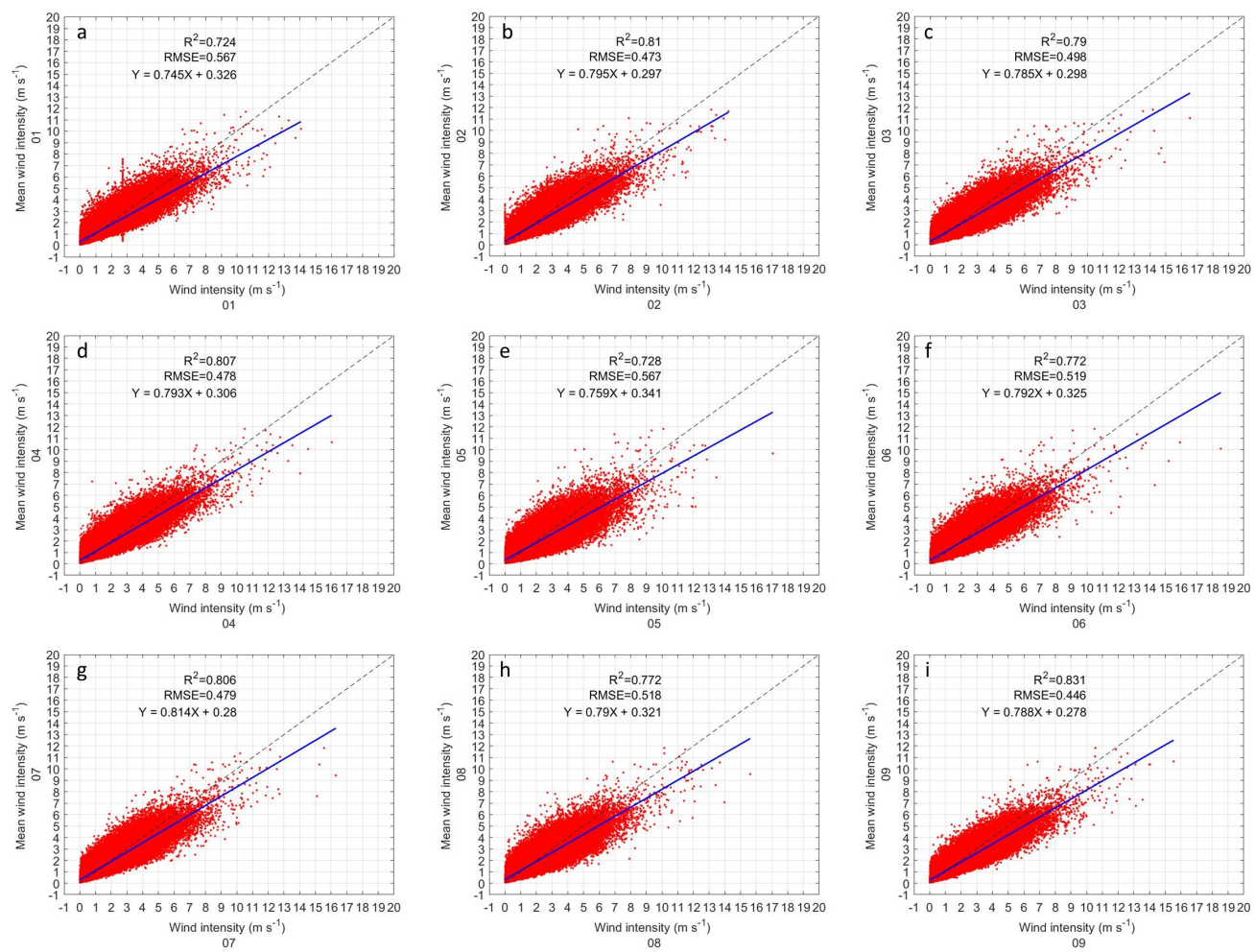

Figure 6. Same as Figure 3 but for wind velocity. 
Table 4. statistical results of the inter-comparison of the Wind Velocity of the GMX500 sensors.

\begin{tabular}{ccccc}
\hline & \multicolumn{4}{c}{ Wind Velocity } \\
Sensor & R2 & RMSE & Slope (a) & Intercept (b) \\
\hline 1 & 0.724 & 0.567 & 0.745 & 0.326 \\
2 & 0.810 & 0.473 & 0.795 & 0.297 \\
3 & 0.790 & 0.498 & 0.785 & 0.298 \\
4 & 0.807 & 0.478 & 0.793 & 0.306 \\
5 & 0.728 & 0.567 & 0.759 & 0.341 \\
6 & 0.772 & 0.519 & 0.792 & 0.325 \\
7 & 0.806 & 0.479 & 0.814 & 0.280 \\
8 & 0.772 & 0.518 & 0.790 & 0.321 \\
9 & 0.831 & 0.446 & 0.788 & 0.278 \\
\hline
\end{tabular}

\subsection{Analysis of WS100}

The analysis of the WS100 sensors is divided into two parts. In the first part the estimation of precipitation is evaluated and in the second part the capacity of the instrument to measure the size distribution of drops (DSD) is evaluated. For the comparison between the WS100 and Parsivel ${ }^{2}$ sensors, the data is separated by rain events. We use the Tokay et al. 5 definition of rain event, as a period separated by at least 2 hours of no-rain period, the rain/no-rain threshold was set as a minimum of 10 drops and a rain intensity of $0.1 \mathrm{~mm} \mathrm{~h}^{-1}$ using Parsivel $^{2}$ as reference. We discard the events whose accumulated total rainfall is less than $1 \mathrm{~mm}$. During the study period, a total of 23 rain events were found.

\subsection{Rainfall rate}

The rain intensity is evaluated by 4 parameters: the total rain, the minutes of rain, the maximum intensity, and the distribution of the instantaneous rain rate. In Figure 7 shows the comparison of the events rain totals, the number of rainy minutes per event, and the event maximum intensity of WS100 versus Parsivel ${ }^{2}$. The statistical results are shown in Table 5. Linear regression has been restricted to calculating the slope because the intercept is assumed to be 0 . In this case, the slope is equivalent to a correction factor.

The first thing that can be noticed from this comparison is that the accumulated rainfall (Figure 7a), despite the fact that there is sufficient similarity between the WS100 sensors, the total rainfall is higher than that registered by the Parsivel ${ }^{2}$. The percent bias and the absolute percent bias in all sensors are between $88 \%$ to $117 \%$ and $89 \%$ to $118 \%$, respectively. Sensor 10 has the lowest bias and sensor 8 has the highest bias. However, the biases of sensor 10 are similar to those of sensor 9 . All sensors except 8 and 10 have a correlation between 0.90 and 0.93 (Table 5). The sensor 8 has the lowest correlation $(89 \%)$ and the highest correlation has the sensor $10(0.97 \%)$. The slope of sensors 1 to 7 is between 2 and 2.2. Sensor 8 has the highest slope (2.3), while sensors 9 and 10 have the lowest slope (1.85).

The number of rainy minutes (Figure $7 \mathrm{~b}$ ) is less than that registered by the Parsivel $^{2}$ in all sensors (average bias between $-14 \%$ and $-18 \%$ ), except sensor 10 that registered slightly more minutes of rain (average bias of $4.4 \%$ ). The absolute percent bias is about 2 to 3 percentage points higher than average percent bias in most sensors, except in sensor 10 (absolute bias 0.41 percentage points higher than average percent bias). The correlation is almost perfect in all sensors, which is 0.99 in sensors 1 to 9 , while sensor 10 has a perfect correlation (correlation equal to 1). The slope is almost the same in sensors 1 to 9 (approximately 0.85), while in sensor 10 it is 1.28 (Table 5).

In the maximum intensity registered (Figure 7c), the average percent bias in the sensors ranges from $139 \%$ to $172 \%$. Sensor 9 has the lower percent bias and the sensor 2 has the highest percent bias. The absolute percent bias is similar to the percent bias in all sensor without exception (between 1 and 7 percentage points higher). The linear correlation in all sensors ranges between 0.81 and 0.89 , the sensor 9 has the lower correlation and the sensor 
2,8 and 10 have the higher correlation. The slope in the maximum intensity ranges from 2.0 to 2.8 , the sensor 10 has the lower slope and the sensor 2 has the higher slope (Table 5).

The statistical distribution of the instantaneous rain rate is shown in Figure 8. The probability distribution (Figure 8a), shows that all the sensors have problems registering values lower than $0.1 \mathrm{~mm} \mathrm{~h}^{-1}$, except sensor 10 which is more similar to Parsivel ${ }^{2}$. The minimum intensity measured by Parsivel ${ }^{2}$ is $0.01 \mathrm{~mm} \mathrm{~h}^{-1}$. Sensors 1 to 9 present peaks in their distribution that stand out especially between 0.1 and $0.2 \mathrm{~mm} \mathrm{~h}^{-1}$, and another between 0.5 and $0.6 \mathrm{~mm} \mathrm{~h}^{-1}$. The pikes are caused by the low sensitivity of the sensors. Sensor 10 has a pair of peaks at lower intensities, one between 0.01 and $0.02 \mathrm{~mm} \mathrm{~h}^{-1}$ and the other between 0.06 and $0.07 \mathrm{~mm} \mathrm{~h}^{-1}$. All the sensors have more agreement to Parsivel $^{2}$ between the intensities of 2 to $5 \mathrm{~mm} \mathrm{~h}^{-1}$, after that value the WS100 sensors register higher intensities. It can be seen in Figure $7 \mathrm{~b}$ how the greatest contribution in cumulative distribution comes from the highest intensities, which generates that the WS100 sensors register greater precipitation in the total rainfall and include greater maximum intensity.
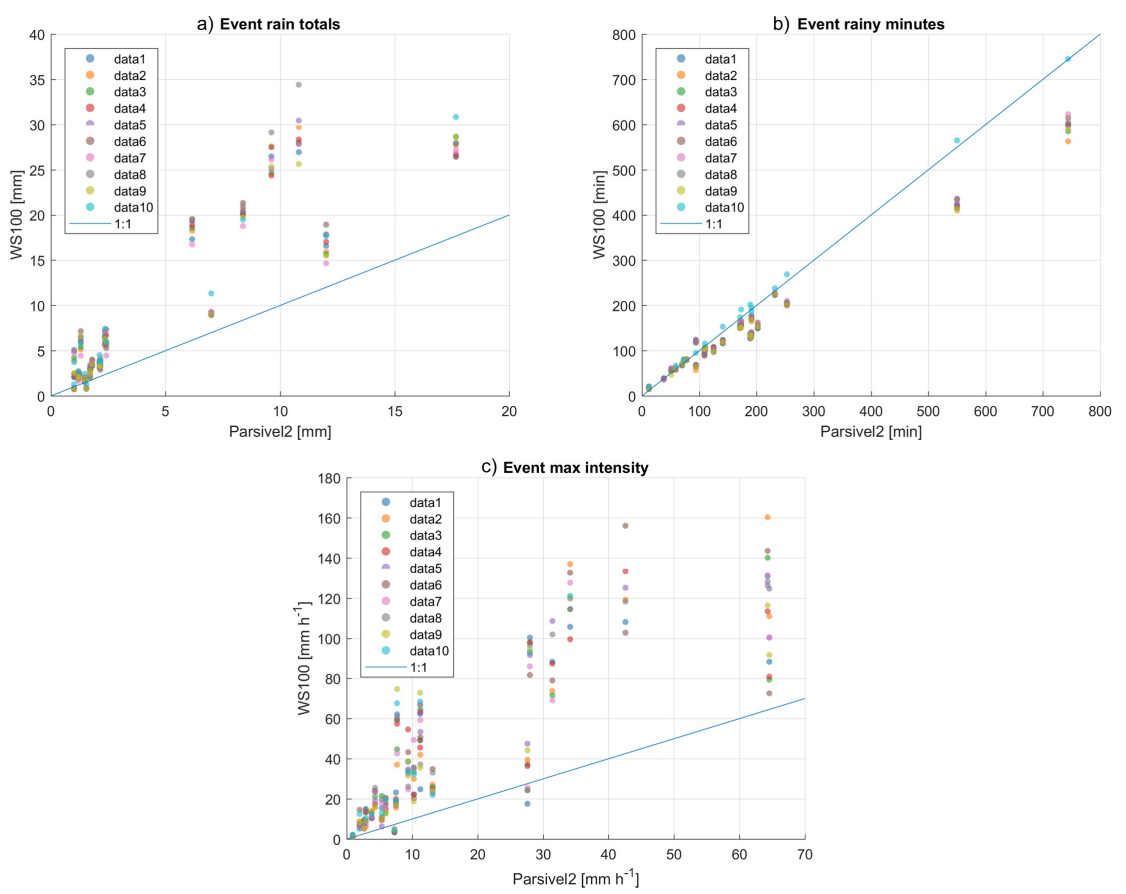

Figure 7. Comparison of ten WS100 sensors with Parsivel $^{2}$ in rainfall events: (a) Accumulated event rain totals greater than $1 \mathrm{~mm}$. (b) Duration of each event in minutes. (c) Maximum intensity registered by each event. Parsivel ${ }^{2}$ is used as reference and 23 events where found. The blue dashed line indicates the 1:1 relation. 

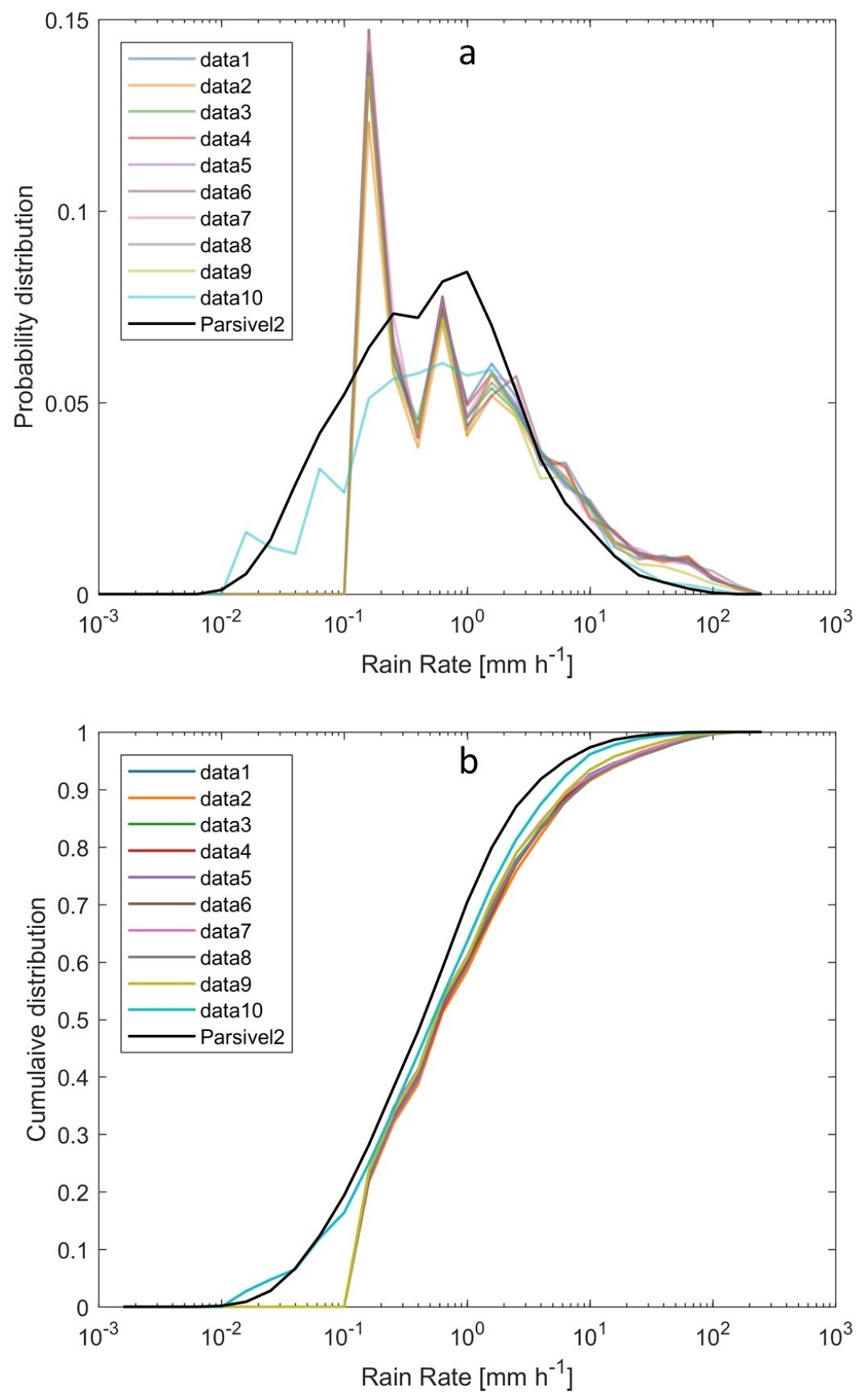

Figure 8. Statistical distribution of rain rate at 1 min sampling output. (a) Probability distribution of rain rate. (b) Cumulative distribution of rain rate. The Parsivel ${ }^{2}$ is shown in black line.

\subsection{Drop Size Distribution (DSD)}

The DSD data output from the WS100 sensors consists of a table with the number of drops for each range of drops. The WS100 sensor has 11 drop size classes ranging from 0.3 to $5.0 \mathrm{~mm}$. The drop size class width is fixed in $0.5 \mathrm{~mm}$, and the last class is reserved to drops greater $\tan 5 \mathrm{~mm}$. The sampling output of $1 \mathrm{~min}$ is used in this work. The number format in the output data is integers and only the number of drops is recorded for each class. The main difficulty in comparing DSD data with WS100 sensors is not possible to represent DSD in standard units, such as number of drops per class width and per volume (i.e., $\mathrm{mm}^{-1} \mathrm{~m}^{-3}$ ). According to the manufacturer, the WS100 sensor's operating principle is 
Table 5. Statistical results of the comparison of the WS100 sensors and Parsivel ${ }^{2}$.

\begin{tabular}{|c|c|c|c|c|c|c|c|c|c|c|}
\hline \multicolumn{11}{|c|}{ Event rain totals } \\
\hline WS100 N & 1 & 2 & 3 & 4 & 5 & 6 & 7 & 8 & 9 & 10 \\
\hline Bias avg. (mm) & 4.36 & 4.69 & 4.39 & 4.39 & 4.68 & 4.77 & 4.20 & 5.13 & 3.84 & 3.90 \\
\hline Bias avg. (\%) & 99.12 & 106.72 & 99.85 & 99.75 & 106.36 & 108.45 & 95.43 & 116.66 & 87.40 & 88.61 \\
\hline Bias abs. (\%) & 100.83 & 108.47 & 101.86 & 101.57 & 108.39 & 110.41 & 97.22 & 118.73 & 89.53 & 89.24 \\
\hline Correlation & 0.92 & 0.90 & 0.92 & 0.91 & 0.90 & 0.91 & 0.91 & 0.89 & 0.93 & 0.97 \\
\hline Slope & 2.102 & 2.237 & 2.114 & 2.141 & 2.186 & 2.235 & 2.067 & 2.313 & 1.855 & 1.852 \\
\hline \multicolumn{11}{|c|}{ Event rainy minutes } \\
\hline WS100 N & 1 & 2 & 3 & 4 & 5 & 6 & 7 & 8 & 9 & 10 \\
\hline Bias avg. (min) & -25.52 & -28.68 & -26.83 & -25.35 & -26.00 & -22.04 & -22.04 & -24.35 & -31.43 & 7.53 \\
\hline Bias avg. (\%) & -14.86 & -16.70 & -15.62 & -14.76 & -15.14 & -12.84 & -12.84 & -14.18 & -18.30 & 4.39 \\
\hline Bias abs. (\%) & 17.09 & 18.77 & 17.75 & 17.19 & 17.72 & 15.22 & 15.62 & 17.06 & 19.08 & 4.70 \\
\hline Correlation & 0.99 & 0.99 & 0.99 & 0.99 & 0.99 & 0.99 & 0.99 & 0.99 & 0.99 & 1.00 \\
\hline Slope & 0.851 & 0.825 & 0.844 & 0.852 & 0.849 & 0.872 & 0.872 & 0.858 & 0.876 & 1.279 \\
\hline \multicolumn{11}{|c|}{ Event max intensity } \\
\hline WS100 N & 1 & 2 & 3 & 4 & 5 & 6 & 7 & 8 & 9 & 10 \\
\hline Bias avg. (mm/h) & 26.05 & 30.92 & 26.04 & 27.23 & 29.98 & 29.97 & 27.10 & 30.38 & 24.08 & 25.50 \\
\hline Bias avg. (\%) & 150.55 & 178.68 & 150.50 & 157.38 & 173.24 & 173.21 & 156.61 & 175.58 & 139.18 & 147.35 \\
\hline Bias abs. (\%) & 157.33 & 180.30 & 154.16 & 159.24 & 175.24 & 174.91 & 158.56 & 179.09 & 140.66 & 149.49 \\
\hline Correlation & 0.84 & 0.89 & 0.85 & 0.82 & 0.87 & 0.82 & 0.86 & 0.89 & 0.81 & 0.89 \\
\hline Slope & 2.506 & 2.825 & 2.505 & 2.574 & 2.732 & 2.732 & 2.566 & 2.756 & 2.283 & 2.049 \\
\hline
\end{tabular}

based on a Doppler radar. Unfortunately they do not provide information on the theoretical bases and technical details necessary to handle the units of the DSD. Note that the DSD retrieval using a vertically pointing Dopper radar is widely documented in the literature (e.g., $[9,14,15])$.

The Figure 9 show the comparison of the DSD retrieved by the Parsivel ${ }^{2}$ and WS100 sensors expressed in number of drops for 23 rain events. The WS100 sensors register very few drops for sizes smaller than $2 \mathrm{~mm}$ and more drops for drop sizes greater than $4 \mathrm{~mm}$. The curves intersect in the drops of medium size, between 2 and $3 \mathrm{~mm}$. In Parsivel $^{2}$ the peaks of the drop concentration are close to $0.5 \mathrm{~mm}$. The distribution in all cases resembles the Gamma DSD model [16]. The DSD recorded in by the WS100 sensors is atypical, because the curve is almost constant from 1 to $5 \mathrm{~mm}$. All profiles show a slight decrease in the amount of drops in the range of 2 to $4 \mathrm{~mm}$ of drop size. The number of drops greater than $4 \mathrm{~mm}$, registered by the WS100 sensors, is greater than what would be expected to be real. 

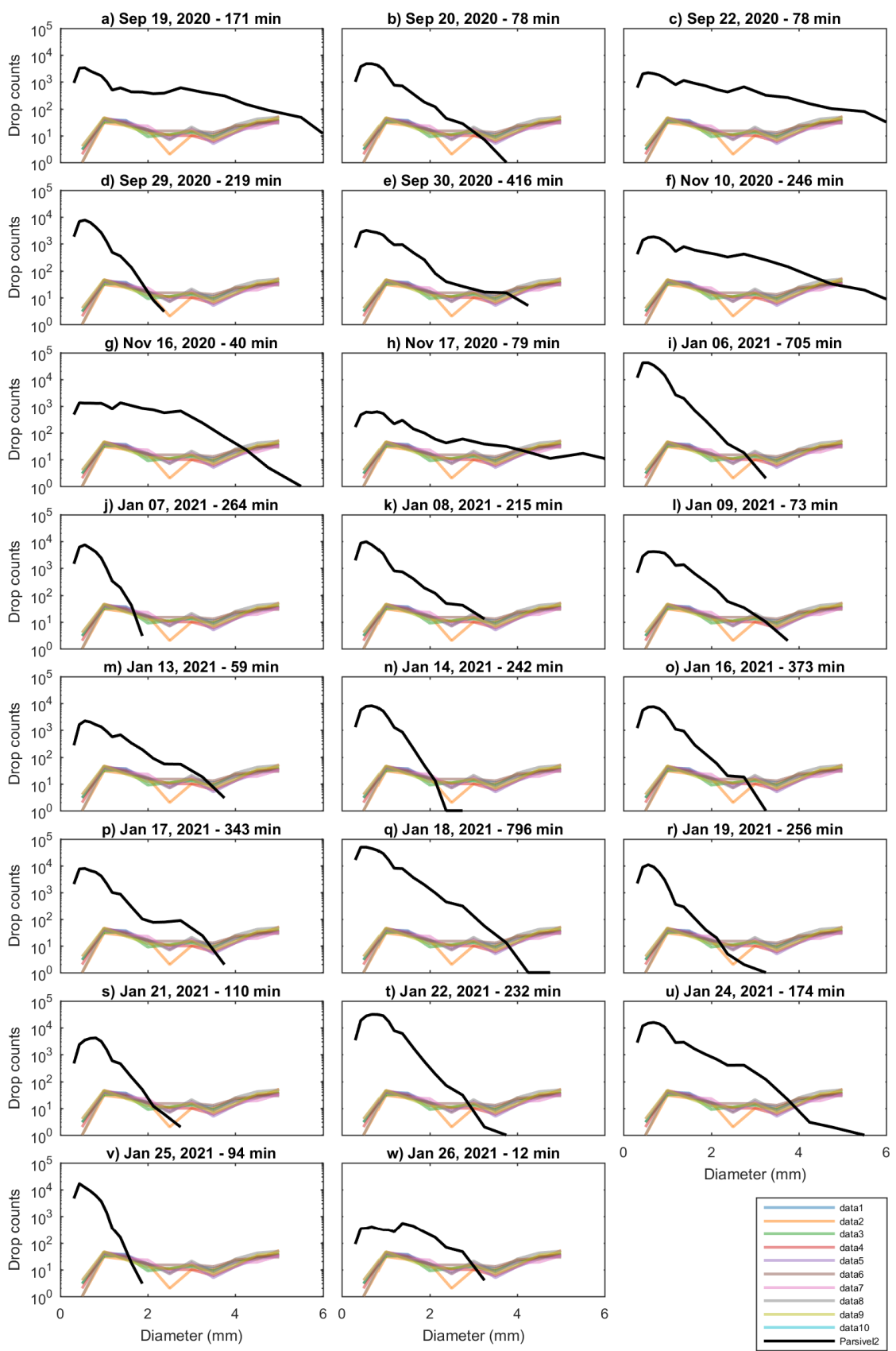

Figure 9. Drop size distribution measured by Parsivel $^{2}$ (black line) and WS100 sensors (color lines) for 23 rainfall events. From a) to w), the DSD for each event is shown.

\section{Discussion}

The results of the inter-comparison of the GMX500 sensors show that sensors 1, 2, and 10 present a considerably higher data dispersion than the others, in many cases the RMSE could be up to 5 times higher (see Tables 1-4). The data dispersion was spatially noticeable in the comparison of the temperature (Figure 3), however, the pressure, relative humidity and wind speed showed outliers (Figures 4-6) that suggested that something in the instrument configuration was wrong. Due to that we decided to increase the study period by carrying out some tests in the configuration within the data loggers during the period of February - March 2021. Fortunately, it was possible to correct the errors caused by a bad configuration of the instruments, however a large amount of data had to be discarded for sensors 1, 2, and 9. Figure 10 shows the inter-comparison of sensor 01 after correcting 
the settings in the data logger. he authors find it important to show how small changes in the configuration can cause measurement errors that can be imperceptible when observing the data in real time. With the optimized configuration, all GMX500 sensors showed great similarity to each other. Sensors RMSE for temperature does not exceed $0.3 \mathrm{C}$, for pressure the RMSE is less than $0.1 \mathrm{HPa}$, for relative humidity the RMSE is less than $1 \%$, except for sensor 5, whose RMSE is $1.3 \%$, and for wind velocity the RMSE is less than $0.6 \mathrm{~m} \mathrm{~s}^{-1}$. The wind velocity present higher variability that other variables, due to it high temporal variability influenced by the turbulence.
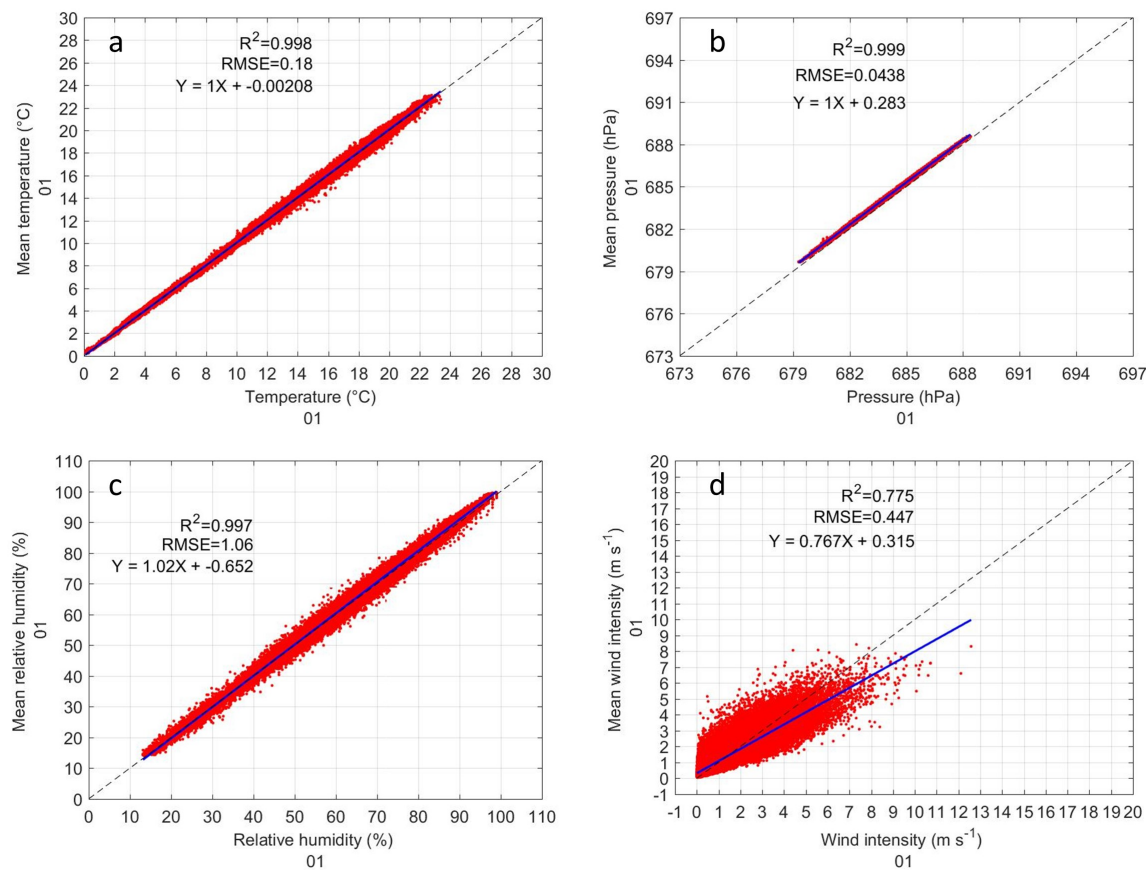

Figure 10. Inter-comparison of GMX500 sensor 01 after correcting the settings in the data logger: (a) Inter-comparison of temperature. (b) Inter-comparison of pressure. (c) Inter-comparison of relative humidity. (d) Inter-comparison of wind velocity.

The event-evaluated rainfall estimate shows that all WS100 sensors overestimate rainfall. The average bias and absolute bias are around $100 \%$, only sensors 8 and 9 have less bias (87\% and 88\%, respectively). The WS100 sensors record fewer rainy minutes than the Parsivel ${ }^{2}$, possibly due to lower sensitivity (Figures 7b, 8). The sensor 10 has shown to have a sensitivity similar to that of Parsivel $^{2}$ and in general terms it has a better estimation of precipitation. Based on how the rainfall intensities are distributed it can be seen that the WS100 sensors have problems in estimating low rainfall intensities. Almost all sensors, with the exception of sensor 10, do not register intensities lower than $0.1 \mathrm{~mm} \mathrm{~h}^{-1}$. For intensities lower than $2 \mathrm{~mm} \mathrm{~h}^{-1}$, peaks were found in the distribution, which would be attributed to the low sensitivity of the instruments. WS100 sensors perform best at intensities between 2 and $5 \mathrm{~mm} \mathrm{~h}^{-1}$ and have the best agreement with Parsivel ${ }^{2}$ measurements. At intensities greater than $5 \mathrm{~mm} \mathrm{~h}^{-1}$, the WS100 sensors overestimate the precipitation, which explains why the error in the maximum intensities is greater than in accumulated rainfall. The slope calculated in the precipitation analysis cannot be used as a correction factor due to the different behavior that the WS100 sensors present at different intensities. The DSD retrieved from the WS100 sensors is very different from that of the Parsive ${ }^{2}$, the similar concentrations in $1 \mathrm{~mm}$ and $5 \mathrm{~mm}$ suggest that there is an error in the estimation of the number of drops, in addition, the flat curve of drop contractions that are observed in all the events is unrealistic (Figure 9). With the information available in the data output, it is not possible to correct the DSD. The authors have requested more information on the technical details of the operation and theoretical bases of the WS100 sensors, which would 
allow correcting all the rainfall estimation parameters. Correction of the DSD of the WS100 sensors and further analysis of the DSD estimate remain for future work.

\section{Conclusions}

In the present work, two sensors that are part of a compact meteorological station have been tested. The GMX500 sensor, whose evaluated variables were: temperature, pressure, relative humidity and wind speed. And the WS100 sensor that is designed to estimate rain and DSD through Doppler radar. With data collected in the period from October 2020 to January 2021, 9 GMX500 sensors were compared. The average of the 9 instruments was used as a reference. In the first evaluation it was found that 2 sensors had a lot of data dispersion with an RMSE up to 5 times higher than the rest. It was found that the errors came from a bad configuration in the data loggers, which led to the extension of the analysis period with different tests between February and March 2021. With the new configuration, it was achieved that all the sensors have the same behavior and the RMSE of the different variables were: Not greater than $0.3 \mathrm{C}$ for temperature, not greater than $0.1 \mathrm{HPa}$ for pressure, and not greater than $1 \%$ for humidity relative (except sensor 5 with $1.3 \%$ ), and not higher than $0.6 \mathrm{~ms}$ for wind speed. The coefficient of determination R2 for all GMX500 sensors were: greater than 0.99 for temperature, greater than 0.99 for pressure, greater than 0.99 for relative humidity, and between 0.72 and 0.81 for wind speed. It has been observed that sensor 5 has slightly lower performance in relative humidity and wind speed, the causes could not be determined.

The WS100 sensors were evaluated using a Parsivel ${ }^{2}$ optical disdrometer as a reference. In the period from October 2020 to January 2021, 9 WS100 sensors were used and one sensor was added in the period of October 2020 to January 2021, as part of a collaboration with the CEPREANDES project. All WS100 sensors were found to overestimate precipitation, with a percent bias close to $100 \%$. The absolute bias is slightly higher with up to 2 percentage points above the percentage bias. It was observed that the differences in the estimates with Parsivel $^{2}$ increase with greater intensity of rain. The minimum intensity detected by the sensors is $0.1 \mathrm{~mm} \mathrm{~h}^{-1}$, except for sensor 10 which resembles that of Parsivel ${ }^{2}$ with $0.01 \mathrm{~mm} \mathrm{~h}^{-1}$. For intensities lower than $2 \mathrm{~mm} \mathrm{~h}^{-1}$, peaks were found in the distribution, which would be attributed to the low sensitivity of the WS100 instruments. At intensities between 2 and $5 \mathrm{~mm} \mathrm{~h}^{-1}$ they have the best agreement with Parsivel ${ }^{2}$. At intensities greater than $5 \mathrm{~mm} \mathrm{~h}^{-1}$, the WS100 sensors overestimate the precipitation, which explains why the error in the maximum intensities is greater than in accumulated rainfall. At intensities lower than $2 \mathrm{~mm} \mathrm{~h}^{-1}$, sublimation of precipitation could be expected due to the low sensitivity of the instruments and an overestimation at intensities higher than $5 \mathrm{~mm} \mathrm{~h}^{-1}$. Due to the behavior of different intensities it is not possible to apply a correction factor. The DSD retrieved by the WS100 sensors have an unrealistic behavior with higher concentrations in diameters of $1 \mathrm{~mm}$ and $5 \mathrm{~mm}$, in addition to presenting a flattened curve. The DSD retrieved by the WS100 sensors have an unrealistic behavior with higher concentrations in diameters of $1 \mathrm{~mm}$ and $5 \mathrm{~mm}$, in addition to presenting a flattened curve. This suggests that the WS100 sensors have errors in the estimation of the number of drops or in the data output. It is hoped that with more information provided by the manufacturers it will be possible to correct the DSD and the other rainfall parameters, which remains as future work.

Author Contributions: Conceptualization, J.L.F.R.; methodology, J.L.F.R., D.A.G., and J.M.V.; software, J.L.F.R., and J.M.V.; validation, J.L.F.R., D.A.G., and J.M.V.; formal analysis, J.L.F.R., and J.M.V.; investigation resources, D.P.G., and Y.F.S.; data curation, D.A.G., and L.F.S.; writing-original draft preparation, J.M.V., and D.A.G.; writing—review and editing, J.L.F.R.; visualization, J.L.F.R., D.A.G., and J.M.V.; supervision, D.P.G., and Y.F.S.; project administration, D.P.G., and R.E.H.; funding acquisition, D.P.G.

Funding: Please add: This research was funded by Universidad Nacional del Centro del Perú UNCP thought CANON y SOBRECANON resources with grant number N2414-CU-2017. 
Data Availability Statement: In this section, please provide details regarding where data supporting reported results can be found, including links to publicly archived datasets analyzed or generated during the study. Please refer to suggested Data Availability Statements in section "MDPI Research Data Policies" at https://www.mdpi.com/ethics. You might choose to exclude this statement if the study did not report any data.

Acknowledgments: The authors thank the personnel of the Huancayo Observatory, Walter Ubaldo Pérez Lino, Manuel Piñas Laura, Susan Mercedes Flores Sanabria, Telésforo Pedro Rojas Ingunza. This work has been made under the proyect "Creación del Centro Científico Tecnológico para prevención de riesgos en zonas alto andinas - CEPREANDES - Sistema Científico - Tecnológico en tiempo real para la toma de decisiones - REALDATA".

Conflicts of Interest: The authors declare no conflict of interest.

\section{References}

1. Matthews, J.; Wright, M.; Clarke, D.; Morley, E.; Silva, H.; Bennett, A.; Robert, D.; Shallcross, D. Urban and rural measurements of atmospheric potential gradient. Journal of Electrostatics 2019, 97, 42-50. doi:https://doi.org/10.1016/j.elstat.2018.11.006.

2. Cheng, W.; Spengler, J.; Brown, R.D. A Comprehensive Model for Estimating Heat Vulnerability of Young Athletes. International Journal of Environmental Research and Public Health 2020, 17, 6156.

3. Danezis, C.; Nikolaidis, M.; Mettas, C.; Hadjimitsis, D.G.; Kokosis, G.; Kleanthous, C. Establishing an Integrated Permanent Sea-Level Monitoring Infrastructure towards the Implementation of Maritime Spatial Planning in Cyprus. Journal of Marine Science and Engineering 2020, 8. doi:10.3390/jmse8110861.

4. Wright, M.; Matthews, J.; Silva, H.; Navasumrit, P.; Ruchirawat, M.; Shallcross, D. Relationship between aerosol concentration, relative humidity and atmospheric electric potential gradient in cities. EGU General Assembly Conference Abstracts, 2020, p. 21927.

5. Tokay, A.; Wolff, D.B.; Petersen, W.A. Evaluation of the new version of the laser-optical disdrometer, OTT parsivel. Journal of Atmospheric and Oceanic Technology 2014, 31, 1276-1288. doi:10.1175/JTECH-D-13-00174.1.

6. Park, S.G.; Kim, H.L.; Ham, Y.W.; Jung, S.H. Comparative evaluation of the OTT PARSIVEL2 using a collocated two-dimensional video disdrometer. Journal of Atmospheric and Oceanic Technology 2017, 34, 2059-2082. doi:10.1175/JTECH-D-16-0256.1.

7. Raupach, T.H.; Berne, A. Correction of raindrop size distributions measured by Parsivel disdrometers, using a two-dimensional video disdrometer as a reference. Atmospheric Measurement Techniques 2015, 8, 343-365. doi:10.5194/amt-8-343-2015.

8. Valdivia, J.M.; Contreras, K.; Martinez-Castro, D.; Villalobos-Puma, E.; Suarez-Salas, L.F.; Silva, Y. Dataset on raindrop size distribution, raindrop fall velocity and precipitation data measured by disdrometers and rain gauges over Peruvian central Andes (12.0S). Data in Brief 2020, 29, 105215. doi:10.1016/j.dib.2020.105215.

9. Valdivia, J.M.; Scipión, D.E.; Milla, M.; Silva, Y. Multi-Instrument Rainfall-Rate Estimation in the Peruvian Central Andes. Journal of Atmospheric and Oceanic Technology 2020, 37, 1811-1826. doi:10.1175/jtech-d-19-0105.1.

10. Del Castillo-Velarde, C.; Kumar, S.; Valdivia-Prado, J.M.; Moya-Álvarez, A.S.; Flores-Rojas, J.L.; Villalobos-Puma, E.; MartínezCastro, D.; Silva-Vidal, Y. Evaluation of GPM Dual-Frequency Precipitation Radar Algorithms to Estimate Drop Size Distribution Parameters, Using Ground-Based Measurement over the Central Andes of Peru. Earth Systems and Environment 2021. doi:10.1007/s41748-021-00242-5.

11. Löffler-Mang, M.; Joss, J. An optical disdrometer for measuring size and velocity of hydrometeors. Journal of Atmospheric and Oceanic Technology 2000, 17, 130-139. doi:10.1175/1520-0426(2000)017<0130:AODFMS>2.0.CO;2.

12. Tokay, A.; D'Adderio, L.P.; Wolff, D.B.; Petersen, W.A. A field study of pixel-scale variability of raindrop size distribution in the Mid-Atlantic region. Journal of Hydrometeorology 2016, 17, 1855-1868. doi:10.1175/JHM-D-15-0159.1.

13. Berne, A.; Krajewski, W.F. Radar for hydrology: Unfulfilled promise or unrecognized potential? Advances in Water Resources 2013, 51,357-366. doi:10.1016/j.advwatres.2012.05.005.

14. Atlas, D.; Srivastava, R.C.; Sekhon, R.S. Doppler radar characteristics of precipitation at vertical incidence. Reviews of Geophysics 1973, 11, 1. doi:10.1029/RG011i001p00001.

15. Peters, G.; Fischer, B.; Andersson, T. Rain observations with a vertically looking Micro Rain Radar (MRR). Boreal Environment Research 2002, 7, 353-362.

16. Ulbrich, C.W. Natural Variations in the Analytical Form of the Raindrop Size Distribution. Journal of Climate and Applied Meteorology 1983, 22(10), 1764-1775. 